\title{
O OBJETO DA IDEOLOGIA NA TEORIA CRÍTICA DO DISCURSO
}

\author{
Maria Eduarda Gonçalves Peixoto*

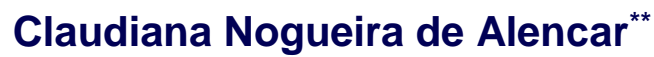 \\ Ruberval Ferreira ${ }^{* * *}$ \\ Universidade Estadual do Ceará \\ Centro de Humanidades \\ Fortaleza, CE, Brasil
}

\begin{abstract}
Resumo: $O$ conceito de ideologia, na segunda metade do século XX, conquistou lugar de destaque nos estudos críticos da linguagem. Entre as principais tradições de investigação na área, a Análise de Discurso Crítica, na vertente da Teoria Crítica do Discurso (FAIRCLOUGH, 1989, 2001, 2003; CHOULIARAKI, FAIRCLOUGH, 1999), particularizase ao situar a noção de ideologia no centro do seu empreendimento teórico-analítico. Com base nisto, este trabalho tem o objetivo de descrever e discutir a constituição conceitual do objeto da ideologia no interior da teoria. Assim, apresentam-se o percurso cronológiconarrativo da abordagem crítica de ideologia, os pressupostos da teoria em foco, a concepção de ideologia articulada e os seus aspectos problemáticos, trazendo à baila alguns desafios que o conceito implica quanto à relação entre discurso e poder.
\end{abstract}

Palavras-chave: Crítica. Ideologia. Discurso. Desafios.

1 INTRODUÇÃO

Tradicionalmente, a forma crítica predominante na história intelectual do ocidente ao longo do século XX, especialmente a partir da influência dos pensadores da Escola de Frankfurt ${ }^{1}$, orientou-se por uma concepção negativa de ideologia. Nessa perspectiva, o termo ideologia foi empregado em referência à fantasia ameaçadora que produz a falsa consciência da realidade no domínio da aparência, tendo como efeito a produção ou a manutenção das relações de assimetrias de poder nas sociedades industriais modernas. De um lado, pela prerrogativa marxista do capital, definiu-se realidade social em termos de um sistema de condições histórico-existenciais mascarado por ideologias hegemônicas. De outro lado, pela arqueologia psicanalítica do sentido, a crítica assumiu a tarefa de

\footnotetext{
*Doutoranda no Programa de Pós-graduação em Linguística Aplicada. E-mail: eduarda.peixoto@uece.br.

** Doutora em Linguística (UNICAMP). Docente do Programa de Pós-graduação em Linguística Aplicada. E-mail: claunoce@gmail.com.

**** Doutor em Linguística (UNICAMP). Docente do Programa de Pós-graduação em Linguística Aplicada. E-mail: ruber.ferreira@uece.br.

${ }^{1}$ Referimo-nos, mais especificamente, a M. Horkheimer, na obra Teoria Tradicional e Teoria Crítica, publicada originalmente em 1937, e a T. Adorno e M. Horkheimer, na obra Dialética do esclarecimento, publicada originalmente em 1947. Ao usarmos o termo "escola", não estamos compreendendo a referida tradição de estudos como um campo doutrinário homogêneo, mas diversificado e composto por reflexões que giram em torno da problemática: sociedade, economia, poder e emancipação.
}

PEIXOTO, Maria Eduarda Gonçalves; ALENCAR, Claudiana Nogueira de; FERREIRA, Ruberval. 0 objeto da ideologia na teoria crítica do discurso. Linguagem em (Dis)curso - LemD, Tubarão, SC, v. 18, n. 1, p. 215-233, jan./abr. 2018. 
descobrir os véus de opacidade das formas ideológicas e revelar os mecanismos reais de produção que determinam a configuração aparente dos sentidos na vida social.

Pressupõe-se, nesta crítica da ideologia, o que podemos chamar de fetichismo linguístico. Os usos linguísticos obliteram a complexa rede de produção dos sentidos ${ }^{2}$ do mesmo modo que as trocas ocultam o processo de produção da mercadoria. Isto é, a lógica pela qual o fetichismo da mercadoria aliena o sujeito de apreender o processo social de determinação do valor dos objetos assemelha-se ao funcionamento mesmo da linguagem, que opera fazendo parecer naturais aos sujeitos significações social e historicamente determinadas. Esta é a forma clássica de conceber a ideologia, em sua relação com o fenômeno da linguagem, que inspirou uma série de transformações nos diversos domínios dos estudos linguísticos críticos, especialmente a partir dos anos 60 e 80.

Das múltiplas tradições que compõem este sinuoso e fértil terreno, a Análise de Discurso Crítica (ADC) particulariza-se em virtude de situar a ideologia como razão de seu vigor crítico, uma vez que uma análise linguística caracteriza-se como crítica à medida que se torna ferramenta para o estudo dos processos ideológicos que medeiam relações de poder e controle na sociedade (KRESS; FOWLER, 1979). Mais especificamente na vertente da Teoria Crítica do Discurso (doravante TCD), que possui como expoente principal o linguista N. Fairclough, a ideologia faz-se conceito elementar e categoria operacional para a investigação transdisciplinar de processos sociais "relacionados às transformações econômicas e culturais contemporâneas" (MAGALHÃES, 2004, p. 113).

Considerando o lugar privilegiado da ideologia no empreendimento teórico da TCD e tendo em vista que a noção carrega um espectro confuso e controverso ao longo da história do pensamento crítico, este artigo tem o objetivo geral de realizar um mapeamento conceitual do objeto da ideologia no interior da teoria em foco. Mais especificamente, pretende-se descrever e discutir a concepção de ideologia mobilizada na TCD, com atenção para três aspectos problemáticos de sua constituição. Primeiro, a compreensão da natureza material da ideologia nas interações sociais como instituída discursivamente, isto é, se se compartilha da ideia de uma fronteira definida entre construções discursivas e processos ideológicos. Segundo, a relação entre ideologia e formas simbólicas, ou seja, se a TCD utiliza a noção de ideologia em referência exclusivamente àquelas formas simbólicas que servem para estabelecer e sustentar relações sistematicamente assimétricas de poder. Terceiro, as motivações ideológicas da própria prática de análise de discurso crítica, sendo possível para a TCD delimitar um espaço desmistificador da crítica no interior da realidade social.

Para dar conta dessa pauta, inicialmente, apresentamos o percurso cronológiconarrativo de desenvolvimento da abordagem negativa de ideologia, pontuando especificamente os momentos determinantes para a construção conceitual do objeto na TCD. Em seguida, discutimos a ontologia do social de que a teoria lança mão para o investimento na categoria da ideologia em sua proposta de análise crítica. Adiante,

\footnotetext{
${ }^{2}$ A respeito da relação entre fetichismo, mercadoria e linguagem, sugerimos as seguintes leituras: Jacques Rancière, em L'inconscient esthétique (Galilée, 2001); Slavoj Žižek, em Menos que nada: Hegel e a sombra do materialismo dialético (Boitempo, 2013), e Vladimir Safatle, em Cinismo e falência da crítica (Boitempo, 2008).
}

PEIXOTO, Maria Eduarda Gonçalves; ALENCAR, Claudiana Nogueira de; FERREIRA, Ruberval. 0 objeto da ideologia na teoria crítica do discurso. Linguagem em (Dis)curso - LemD, Tubarão, SC, v. 18, n. 1, p. 215-233, jan./abr. 2018. 
explanamos o modo como a TCD delimita a categoria, quanto a questões de definição, localização nos fatos da linguagem, natureza semiótica e tratamento analítico. Por fim, encerramos nosso debate trazendo à baila alguns aspectos problemáticos em torno da concepção de ideologia na TCD, que merecem atenção cuidadosa para uma reflexão cada vez mais ampliada sobre discurso e poder.

A razão última que motiva este trabalho é argumentar que a ideologia, para além de uma leitura sintomal da realidade, precisa ser pensada em relação aos desafios que o conceito implica no interior dos estudos críticos da linguagem.

\section{BREVE ARQUEOLOGIA DA CONCEPÇÃO NEGATIVA DE IDEOLOGIA}

Nesta seção, iniciamos nosso debate apresentando o percurso cronológico-narrativo da concepção negativa de ideologia. Nossa intenção, aqui, não é esgotar a história do conceito de ideologia, mas selecionar e narrar aspectos de algumas teorizações acerca da categoria que consideramos relevantes para a compreensão do modo como o termo é apropriado, adiante, pela TCD.

\subsection{K. MARX}

A abordagem negativa da ideologia conquistou terreno somente a partir dos estudos do filósofo alemão Karl Marx, que, na segunda metade do século XIX, redesenhou o termo dentro de um referencial teórico bastante particular, orientado por um programa político de revolução social, tornando o conceito um instrumental necessário para a análise da sociedade e sua mudança. Familiarizados com diversas entidades e movimentos operários em vários países europeus ocidentais, K. Marx e F. Engels publicaram A ideologia alemã (1999), rebatendo a visão positiva de ideologia que L. Feuerbach, B. Bauer e M. Stirner, entre outros hegelianos, defendiam.

Para os autores do materialismo histórico, a crise do mundo ocidental, especialmente na Alemanha, passava ao largo de ser uma batalha de ideias alheias às condições sociais e históricas da vida humana. Desse modo, Marx e Engels empenharamse para mostrar que a ideologia só pode emergir da divisão do trabalho e da cisão de classes, fundando, assim, o tipo de abordagem negativa de ideologia ou crítica da ideologia, que nos faz compreender o fenômeno ideológico como sendo um compêndio de ideias (resultado do trabalho intelectual, em oposição ao trabalho físico) utilizado para servir às relações de dominação presentes nas sociedades capitalistas.

Marx concedeu a estrutura da sociedade como uma organização constituída por instâncias e níveis, articulados por determinações específicas. Na instância da infraestrutura, encontram-se as unidades das forças produtivas e das relações de produção, em seus distintos níveis. Na instância da superestrutura, encontram-se a lei e o estado, compondo o nível jurídico-político, e as ideologias (as ideias religiosas, éticas, filosóficas, políticas, etc.), compondo o nível ideológico. Por esse diagrama, advoga-se que as ideias, sistematizadas nas ideologias, não se desenvolvem por si mesmas, mas a partir da base de forças e relações de produção da infraestrutura. Ao defenderem, 
contrariando o humanismo naturalista de Feuerbach, que a essência humana consiste no conjunto das relações sociais e que estas surgem do trabalho e da intervenção dos homens sobre a natureza, Marx e Engels argumentam que a "produção de ideias, de representações e da consciência está, em primeiro lugar, direta e intimamente ligada à atividade material e ao comércio material dos homens" (MARX; ENGELS, 1999, p. 20).

Quando Marx e Engels definem, nesses termos, que ideologia é consciência falsa da realidade, eles estão afirmando, sobretudo, que ideologia é consciência. Assim, a ideologia é, paradoxalmente, linguagem da vida real e também sua inversão, à medida que, se nela os seres humanos e as suas relações aparecem invertidos, tal como ocorre numa câmera obscura, isso é apenas “o resultado do seu processo de vida histórico, do mesmo modo que a imagem invertida dos objetos que se formam na retina é uma consequência do seu processo de vida diretamente físico" (MARX; ENGELS, 1999, p. 21). Especialmente para Marx, toda formação social surge de um determinado modo de produção dominante, de forma que são os processos de produção que movimentam as forças produtivas, uma vez que a condição elementar da produção é a reprodução das condições de produção (meios de produção, força de trabalho e outras relações). As instituições (tais como igreja, família e escola) têm, pois, a função de assegurar as sujeições às ideologias dominantes, mantendo e naturalizando as condições de produção.

A partir da ruptura que Marx e Engels empreenderam quanto à tradição do pensamento científico, ao fundarem uma ciência da história, com uma nova e ousada forma lógica de produção de conhecimento, o materialismo dialético, os estudos sobre ideologia passaram a compor um importante horizonte para a compreensão da relação entre consciência e realidade (ou entre sujeito e objeto), tão cara à filosofia em particular e às ciências em geral. Essa relação entre percepção/sujeito/consciência, de um lado, e realidade em si, de outro - oposição tal como colocada por Marx, pertencente à engenharia do modus operandi da ideologia - só será pesquisada mais densamente anos depois, com o filósofo Louis Althusser, na década de 60 do século XX, momento em que o estruturalismo consolidou-se nas ciências humanas e sociais.

\subsection{ALTHUSSER}

Vimos que, para Marx, a ideologia é um construto ilusório, falso, que tem a realidade como seu oposto, o que implica dizer que verdade e história lhe são externas. Se se parte dessa premissa geral, então, admite-se que, uma vez que as ideologias não correspondem à realidade, embora a elas se refiram efetivamente, é preciso interpretá-las e revelar seus processos de produção, para que se descubra, enfim, a verdade real do mundo, mascarada pela representação imaginária. Esta seria a tarefa da crítica, por excelência. Diante desse quadro, Althusser combate a abordagem da ideologia como falsa consciência da realidade social, definindo-a enquanto dimensão organicamente constituinte das estruturas das sociedades: "as sociedades humanas segregam a ideologia como o elemento e a atmosfera mesma indispensável à sua respiração, à sua vida histórica" (ALTHUSSER, 1985, p. 239). 
A primeira lição que extraímos dessa definição é que - enquanto para Marx, nós criamos representações alienadas de nossas reais condições de existência porque tais condições (de trabalho) são alienantes - para Althusser, o que fazemos não é representar tais condições de existência, mas a nossa relação com elas: não são as suas condições reais de existência, seu mundo real que os homens representam na ideologia, "o que nela é representado é, antes de mais nada, a sua relação com as condições reais de existência" (ALTHUSSER, 1985, p. 127). A fronteira entre o real e o imaginário, considerada por Marx uma linha definidora do modo de operação da ideologia pela falsa consciência da realidade, é seriamente rompida por Althusser (1985), com o advento da concepção de prática. Prática, segundo o filósofo, é todo processo de transformação de uma matériaprima em produto através do trabalho humano realizado por determinados meios de produção. É nesse sentido que a ideologia é compreendida como um nível do modo de produção da sociedade.

Entendamos o raciocínio que Althusser (1985) desenha para nós: presumindo que toda realidade social se constitua a partir de modos de produção dominantes e que, portanto, é o processo mesmo de produção que movimenta as forças produtivas, decorre que a formação da sociedade, ao mesmo tempo em que produz (e para produzir), deve reproduzir as suas condições de produção. Isto não é outra coisa senão o funcionamento mesmo da ideologia. As práticas de (re)produção consistem na materialidade da ideologia (ideologia é prática), uma vez que toda prática existe através de e sob uma ideologia. Quem garante a reprodução das relações de produção, sob formas contraditórias e sobredeterminadas, são os Aparelhos Ideológicos de Estado (AIE). Os AIE referem-se a um certo número de realidades que "se apresentam ao observador imediato sob a forma de instituições distintas e especializadas" (ALTHUSSER, 1970, p. 115), tais como o aparelho ideológico religioso e o familiar, entre outros.

Os AIE distinguem-se dos Aparelhos Repressivos de Estado, uma vez que estes últimos operam geralmente pela violência (visível, física e objetiva) em domínios da vida pública, enquanto os AIE operam pela ideologia, predominantemente, em domínios da vida privada. Diz-se "predominantemente" porque, como bem ressalva o filósofo, os AIE também funcionam pela repressão, disfarçada ou simbólica. O ponto de contato entre ambos os tipos de aparelhos é que os repressivos asseguram a atuação dos ideológicos. Trazendo a noção de prática para pensar essa questão, fica claro, pois, que a unidade dos diferentes aparelhos ideológicos é mantida pelas ideologias dominantes (isto é, ideologias das classes dominantes), pois elas compõem a área de interação, sempre tensa e contraditória, entre os aparelhos repressivos e os aparelhos ideológicos, bem como entre os distintos aparelhos ideológicos.

A materialidade da ideologia na formação simbólica e sobredeterminada das sociedades - materialidade que só existe em aparelhos e em suas práticas regidas por rituais determinados ${ }^{3}$ - tem como mecanismo de realização o processo discursivo de interpelação (o próprio processo de sujeição), que, em última instância, serve à

\footnotetext{
${ }^{3}$ Por isso, Althusser (1985) prefere falar em teoria da ideologia em geral, em oposição a uma teoria das ideologias particulares, porque aquela está interessada em discutir o mecanismo geral ou universal pelo qual qualquer ideologia opera, isto é, a partir da reprodução das relações materiais de produção.
} 
reprodução das relações de poder da vida social, ao produzir as evidências do sujeito e do sentido. Os AIE prescrevem "práticas materiais reguladas por um ritual material, práticas que existem nos atos materiais de um sujeito" (ALTHUSSER, 1985, p. 92). Nesses termos, Althusser argumenta, a partir da referência à psicanálise lacaniana, que a ideologia opera por uma estrutura de dupla relação especular, posto que "toda ideologia existe pelo sujeito e para o sujeito" (ALTHUSSER, 1985, p. 209). Maneira de dizer que o sujeito é, a um só tempo, o sujeito da ação e o sujeito sujeitado ao Sujeito, ao Outro (que é uma ideologia) como composto por redes de valores e crenças que o interpelam cotidianamente: "toda a ideologia tem um centro, o Sujeito Absoluto ocupa o lugar único do centro e interpela, à sua volta, a infinidade dos indivíduos como sujeitos, em uma dupla relação especular" (ALTHUSSER, 1976, p. 118).

A constituição dos sujeitos dá-se, assim, pelos processos simultâneos e necessários de reconhecimento e de desconhecimento. Quando o indivíduo se reconhece como sujeito em e por um discurso - há o reconhecimento mútuo entre os sujeitos e o Sujeito, bem como entre os próprios sujeitos, e há o reconhecimento do sujeito por si mesmo - ele desconhece a sua submissão ao Sujeito, isto é, reconhece-se apenas sob a condição do desconhecimento de sua submissão, sob a condição de que "se os sujeitos reconhecerem o que são e se conduzirem de acordo, tudo irá bem" (ALTHUSSER, 1976, p. 119). A função principal da interpelação é, portanto, a de "conduzir sua auto-sujeição [a do sujeito] ao sistema dominante e, por essa via, assegurar a reprodução social em seu conjunto" (LACLAU, 1979, p. 106).

Embora Althusser tenha inaugurado, na tradição do pensamento crítico, o gesto de conceber a ideologia como prática e de indicar o seu funcionamento por mecanismos simbólico de interpelação, a partir de aparelhos ideológicos e de seus rituais, é somente com o trabalho do filósofo francês Michel Pêcheux que a prática material da ideologia será melhor explorada em sua natureza linguístico-discursiva.

\subsection{PÊCHEUX}

Na década de 70, quando M. Pêcheux, em parceria com o linguista C. Fuchs, aprimora a chamada Análise Automática do Discurso (AAD), à procura de melhor acordar a relação entre os estudos linguísticos e a teoria do discurso e de realizar algumas alterações no quadro epistemológico geral de sua teoria, a AAD avança em sua tarefa crítica: o interesse maior é o modo como os textos significam, em clara oposição ao objetivo da análise de conteúdo, que era o de saber o que os textos querem significar. Para dar conta desta pauta, Pêcheux articula três regiões do conhecimento científico, que servem para sustentar o seu empreendimento quanto a três questões centrais de sua crítica. Primeiro, o referencial teórico-conceitual do materialismo histórico, que serve à ontologia crítica da sociedade de que Pêcheux lança mão para pensar a formação social e a sua transformação. Segundo, o referencial da linguística estruturalista, que serve como teoria de análise dos mecanismos de sintaxe e de enunciação. Terceiro, a teoria do discurso, que serve como referencial conceitual para a compreensão da determinação histórica dos processos de significação. Com mais atenção, podemos notar que a AAD tem como pilares de fundamentação conceitos que foram anteriormente explorados por L. Althusser, sobretudo, sociedade, ideologia e discurso. 
Resgatando o ponto de vista de L. Althusser acerca da materialidade da ideologia, Pêcheux tem o propósito de desenvolver uma explicação acerca das condições ideológicas de reprodução/transformação das relações de produção segundo uma teoria materialista do discurso. $\mathrm{O}$ autor compreende que esta materialidade é articulada sobre a materialidade econômica. Isso significa dizer que o funcionamento da instância ideológica é determinado pela instância econômica, uma vez que a ideologia aparece "como uma das condições (não-econômicas) da reprodução da base econômica, mais especificamente das relações de produção inerentes a esta base econômica" (PÊCHEUX; FUCHS, 1997, p. 165). Entendendo que tal mecanismo de reprodução opera por processos de interpelação assegurados por AIE, conforme argumenta L. Althusser, Pêcheux (1996) explica que, em determinados momentos da história, a contínua reprodução das relações de classe é rompida quando as classes são marcadas por graves afrontamentos políticos e ideológicos dentro dos AIE's. Daí a necessidade de se pensar em formações ideológicas (FI).

Uma FI é um conjunto complexo de atitudes e de representações "que não são nem 'individuais' nem 'universais', mas se relacionam mais ou menos diretamente a posições de classe em conflito umas com as outras" (PÊCHEUX; FUCHS, 1997, p. 166, grifo dos autores). Assim, as FI's são compostas por formações discursivas (FD's), instâncias sociais e culturais que determinam, em distintos contextos, "o que pode e deve ser dito" (PÊCHEUX, 1995, p. 160, grifo do autor). Segundo Pêcheux, a formação ideológica caracteriza o aspecto da luta no interior dos aparelhos de controle, pois diz respeito às forças em confronto na conjuntura ideológica característica de uma formação social em determinado momento (PÊCHEUX; FUCHS, 1997). Nesses termos, o processo de reprodução/transformação deve ser encarado a partir da ideia de que qualquer forma de produção/transformação baseada na luta de classes é intrinsecamente contraditória. Maneira de dizer que não se pode falar em aspectos que contribuem exclusivamente para a reprodução ou exclusivamente para a transformação, dado que a luta de classes atravessa os AIE's.

Isso significa que não há uma correspondência de um para um entre ideologias e classes (no sentido de que cada classe teria sua própria ideologia) e que os AIE não são a realização ou a expressão de uma ideologia dominante (isto é, ideologia de uma classe dominante) ou de uma ideologia em geral (um tipo de zeitgeist imposto a priori). Os AIE são, antes, local e meio de realização da dominação: "é através da instauração dos Aparelhos Ideológicos de Estado, em que essa ideologia [a ideologia da classe dominante] é realizada e se realiza, que ela se torna a dominante" (PÊCHEUX, 1996, p. 144). Portanto, os AIE compõem, de modo simultâneo e contraditório, o local e as condições ideológicas da reprodução e da transformação das relações de produção na sociedade.

Nesses termos, faz-se útil pensar a ideologia quanto a formações ideológicas, que se dão regionalmente em distintos domínios (como escola, religião, família) marcados por relações de desigualdade e de subordinação, envolvendo não apenas os objetos ideológicos, mas também seus modos de uso, isto é, suas práticas. As relações de desigualdade e subordinação entre as diferentes regiões dos AIE constituem, pois, a luta ideológica de classes, de tal modo que a transformação das relações de produção só é possível no interior mesmo do complexo em que consistem tais aparelhos, quando se impõem novas relações de desigualdade e subordinação. 
Sendo a ideologia, em síntese, a relação entre humanos organizados socialmente, no sentido específico de não ser um fenômeno natural e essencial, o ideológico é eterno, tal como o inconsciente, porque, como este, opera pela ocultação de sua própria existência. Esse mecanismo comum entre o ideológico e o inconsciente, que se dá na formação do sujeito por interpelação, gera, como coloca Pêcheux, as chamadas verdades evidentes. Este é o efeito último da ideologia: a evidência, na produção do sentido e na constituição do sujeito.

Esse caminho de desenvolvimento de visões críticas ou negativas de ideologia, em sua cada vez mais estreita relação com o discurso - tal como revela uma das máximas do Círculo de Bakhtin segundo a qual o signo linguístico é a realidade material por excelência da criação ideológica, uma vez que consiste na arena onde se dão lutas de classe - será problematizado, mais adiante, por J. B. Thompson. Para ao autor, há um elemento importante que, tendo estado na base da concepção marxista de ideologia, perdeu-se na literatura mais recente da teoria social e política, sendo, pois, necessário recuperá-lo: este elemento é o critério de "sustentação das relações de dominação" (THOMPSON, 1995, p. 76). Assim, a questão ideológica passa a ser encarada por meio de uma abordagem crítica ou negativa que dá ênfase a relações e práticas em que o sentido é investido em termos de assimetrias de poder.

\subsection{J. B. THOMPSON}

A ideologia é "o sentido a serviço do poder" (THOMPSON, 1995, p. 16). Através dela, formas simbólicas tornam-se um "espectro de ações e falas, imagens e textos, que são produzidos por sujeitos e reconhecidos por eles e outros como construtos significativos" (THOMPSON, 1995, p. 79). Assim, para Thompson, as formas simbólicas tornam-se ideológicas apenas quando, em determinados contornos históricos e contingenciais, são mobilizadas em discursos para estabelecer e sustentar relações de dominação e controle.

Já aqui podemos notar que Thompson redescreve a perspectiva marxista de ideologia segundo a forma particular com que o autor reconstrói os pressupostos referentes à associação entre transformação cultural e sociedade industrial moderna, as formas culturais da sociedade moderna: "o desenvolvimento de um conjunto de instituições relacionadas com a produção e com a distribuição massivas de bens simbólicos" (THOMPSON, 1995, p. 113). Para o autor, houve nas últimas décadas um uso generalizado e neutralizado do termo ideologia, que nos fez pensar o conceito relacionado a doutrinas políticas específicas, a regimes políticos isolados ou a determinados sistemas simbólicos. Trata-se de um engano, como argumenta Thompson (1995), que desvia nossa atenção para a verdadeira natureza e papel da ideologia: há variadas maneiras pelas quais as formas simbólicas são utilizadas para estabelecer e sustentar relações de poder em diversos contextos.

O termo ideologia, assim, não deve ser empregado como um conjunto de valores e crenças que submente indivíduos à ordem social, porque o modo como formas simbólicas servem ao poder é muito mais complexo e dinâmico. O que deve ser objeto de 
preocupação da crítica é, para Thompson (THOMPSON, 1995, p. 124), examinar "as maneiras como as pessoas localizadas diferencialmente na ordem social respondem e dão sentido a formas simbólicas específicas" e, consequentemente, como essas formas simbólicas, analisadas dentro dos contextos de produção, consumo e compreensão, "servem (ou não servem) para estabelecer ou sustentar relações de dominação".

Há, nessa direção, três aspectos importantes para a recuperação do emprego da ideologia pela teoria social e política. Primeiro, ao enfatizar as relações de poder, o autor rompe com a tese clássica da luta de classes como antagonismo estruturante da sociedade. A preocupação, agora, é mostrar que há outras formas de desigualdade e de exploração a que as ideologias servem, como tensões de gênero e de etnia. Segundo, ao chamar a atenção para as formas simbólicas, o sociólogo evidencia que elas não são representações ou reflexos da realidade, mas elementos constitutivos dela, engajados nos processos de criação e de reprodução de relações e de práticas sociais diversas. Há, ainda, um terceiro aspecto, que fornece tanto um horizonte teórico, pelo qual se compreende a ideologia, quanto uma orientação metodológico-analítica, que sugere examiná-la a partir dos seus modos de operação reiterados nas interações ou quase-interações (THOMPSON, 1995, p. 81).

Quanto a este último aspecto, pode-se falar de mecanismos e estratégias predominantemente empregados nas produções simbólico-discursivas da vida social: i) a legitimação, realizada por meio de estratégias de racionalização, de universalização e de narrativização; ii) a dissimulação, cujas estratégias são a eufemização, o deslocamento e o tropo; iii) a unificação, que consiste na simbolização de coletividades sociais; iv) a fragmentação, possibilitada por recursos de diferença e de expurgo do inimigo, que criam fronteiras entre grupos sociais; e v) a reificação, como modo de naturalizar ou universalizar situações e acontecimentos.

Conceber a ideologia do ponto de vista das lutas de poder, em sua relação com formas simbólicas e com mecanismos discursivos de operação, passa a servir bem aos propósitos de pesquisa da ADC em geral e da TCD em particular, considerando sua agenda de investigação orientada para a mudança social. Para compreendermos de que maneira, então, a TCD investe no objeto da ideologia em sua abordagem crítica, precisamos situar o lugar de onde a teoria, menos por filiações disciplinares que por diálogos, assume uma postura que se possa caracterizar como crítica.

\section{A PROPÓSITO DA CRÍTICA: TEORIA CRÍTICA DO DISCURSO E REALISMO CRÍTICO}

Longe de supor que a forma crítica possua um percurso bem definido na história intelectual, compreendemos que fazer crítica, como bem lembra M. Foucault (1997) no ensaio What is Critique?, é algo que não cessa de se formar, de nascer e renascer pelas veredas da filosofia ou, como diz o autor, no lugar de toda possibilidade de filosofia. Marcada por contingências, lutas por significação e gestos de investimentos e interesses os mais variados, a forma crítica, certamente, pode ser abordada de distintos modos e fins. Tendo em vista que o conceito de ideologia justifica o esforço de crítica empenhado pela 
TCD e que toda crítica precede uma ontologia da realidade social e de sua relação com a linguagem como semiose, o caminho que escolhemos neste trabalho para delimitar a forma crítica apresentada pela teoria em foco parte da explanação da conexão conceitual entre realidade e linguagem desenvolvida no Realismo Crítico, cujos princípios ontológicos fundamentam a ADC em geral e a TCD em particular (FAIRCLOUGH; JESSOP; SAYER, 2002).

Para o RC, a realidade social não pode ser concebida pelas ciências como uma entidade imutável, dotada de uma positividade ou literalidade última, nem como totalidade imediata e inteiramente observável, uma vez "as propriedades que tornam sociedades possíveis objetos de conhecimento pressupõem ação humana e mutabilidade" (RAMALHO, 2008, p. 02). Com base nesta premissa, Bhaskar entende que a realidade só pode ser acessada pelo esforço científico através da mediação do conhecimento. Havendo, portanto, uma distinção entre a realidade e o conhecimento acerca dela, temos as seguintes lições extraídas: i) não se conhece tudo o que há, ii) não se pode reduzir o que há ao conhecimento construído a propósito do que existe e iii) a realidade social não é produto direto e imediato das ações dos sujeitos, pois a relação entre estruturas sociais e ações só é possível por processos de mediação ou instanciação, constituídos sincrônica e diacronicamente. Para pensar a realidade social, que consiste irreversivelmente em um sistema aberto, os realistas críticos propõem, então, uma ontologia estratificada do mundo, isto é, o mundo é racionalizado como sendo "estratificado - isto é, estruturado, diferenciado - e mutável" (BHASKAR; CALLINICOS, 2007, p. 98).

Nessa direção, Bhaskar e Callinicos (2007, p. 98) descrevem o sistema aberto da vida social como operado em distintos domínios ontológicos (o real, o actual e o empírico) e em diversos estratos e subestratos organizacionais (físico, químico, biológico e semiótico, entre outros). O domínio do real ou potencial abrange tudo o que é possível, considerando a natureza (ao mesmo tempo, de possibilidades e de constrangimentos) das estruturas que compõem a tessitura da realidade social. Segundo Sayer (2000, p. 09), o real consiste no que quer que exista, natural ou social, "independentemente de ser um objeto empírico para nós e de termos uma compreensão adequada de sua natureza". O domínio do actual ou realizado, por sua vez, engloba o que acontece, através da realização ou efetivação dos poderes e seus efeitos causais. Como esclarece Sayer (2000, p. 10), o actual refere-se ao que acontece "se e quando estes poderes são ativados", situando-se entre a instância social mais abstrata (a estrutura) e a instância social mais concreta e particular (a ação). O domínio do empírico, por fim, diz respeito ao que conhecemos, àquilo do real e do actual que é experienciado pelos sujeitos.

Os três domínios mencionados funcionam simultaneamente a partir de mecanismos gerativos. Tais mecanismos gerativos consistem em poderes causais, não em relações teleológicas estabelecidas por um tipo de lei determinista ou por uma regularidade necessária, como um julgamento apressado pode supor. A realidade social é tida como governada por mecanismos operacionais, que são os poderes gerativos, de modo tal que as dimensões e os níveis da vida (social e natural, em sua interseção) têm estruturas particulares, que geram (de forma complexa e imprevisível) efeitos através de seus mecanismos de funcionamento. $\mathrm{O}$ que se diz com isso é que, dado que o mundo não corresponde ao "espectro de nossos sentidos, sendo idêntico àquilo que experimentamos" (SAYER, 2000, p. 9), nossa capacidade de empiria não consegue esgotar o que existe ou 
o que poderia existir. Assim, em vez de confiarmos somente no critério de observabilidade, devemos considerar o critério de causa, como defende Collier (1994), compreendido em termos de efeitos imprevisíveis gerados.

A partir dessa perspectiva, Bhaskar (1989, p. 34), influenciado pela tradição marxista, define sociedade em termos de transformação, ou seja, de uma relação causalmente interdependente ou dual entre estruturas e práticas: a sociedade é, ao mesmo tempo, "condição sempre presente (causa material) e o resultado continuamente reproduzido da agência humana". Quanto à agência dos sujeitos, tem-se que a práxis é a produção (consciente) e a reprodução (normalmente inconsciente) das condições de produção que constituem a própria sociedade. Observemos que a concepção transformacional de realidade social em Bhaskar aponta para um elemento que se tornará fundamental para a ADC em geral e para a TCD em particular: o conceito de prática social. Motivado por esta inspiração, Fairclough (2003, p. 14) esclarece o consórcio realizado com o RC e a direção por que delimita a concepção tridimensional de realidade social em termos de estruturas, práticas sociais e eventos do seguinte modo: "tanto eventos sociais concretos como estruturas abstratas, assim como as menos abstratas 'práticas sociais', são parte da realidade".

Para Fairclough (2003), o evento social é uma atualização de possibilidades estruturais, pois se trata de acontecimentos particulares, situados social e historicamente, que envolvem sujeitos atuando uns sobre os outros e sobre o mundo em contextos específicos. As estruturas sociais consistem nas condições históricas de fundação ou instituição da vida social, compondo-se por ordens de discurso, que selecionam, regulam e redistribuem discursos, determinando o que pode e o que deve ser dito. A relação entre estruturas e eventos não é, de forma alguma, de simples determinação, mas altamente complexa, dinâmica e dialética. As estruturas sociais definem, relativamente, as possibilidades de realizações nas práticas, que, por sua vez, restringem os eventos. Em contrapartida, ao atuarem e decidirem nos eventos que acontecem, os sujeitos podem, em um movimento dialético, rearticularem práticas e, com o tempo e sob determinados efeitos, estruturas sociais. Entre o evento e a estrutura, há, pois, as práticas sociais, que são "modos habituais, ligados a perspectivas temporais e espaciais específicas, em que os indivíduos aplicam recursos (materiais ou simbólicos) para agirem em conjunto no mundo" (CHOULIARAKI; FAIRCLOUGH, 1999, p. 21).

Assim dispostos estrutura, prática e evento no sistema aberto da vida social, o discurso é considerado, então, a forma de mediação entre a realidade social e a língua. Discurso situa-se na ordem do discurso (FOUCAULT, 1996), que se refere à "totalidade de discursos em uma sociedade ou instituição, à inter-relação entre as práticas sociais, às articulações e rearticulações entre elas" (MAGALHÃES, 2000, p. 91). Uma vez que os discursos são formados por momentos e elementos internalizados e articulados em práticas, é o jogo de articulações e rearticulações que determinam a produção e a transformação de discursos. Este jogo não é outra coisa senão uma luta hegemônica. Precisamente aqui, encontramos o lugar da ideologia na ontologia do social desenhada pela TCD com base no RC: a "hegemonia depende do investimento e do reinvestimento ideológico das convenções discursivas, dos gêneros discursivos e dos estilos" (MAGALHÃES, 2000, p. 91). Logo, ideologia é o termo central para a compreensão e a análise críticas da linguagem em uso no mundo social. 
Compreendido o percurso pelo qual a concepção negativa de ideologia veio a se tornar central na TCD e explanada brevemente a ontologia do social de que a teoria lança mão para fundamentar sua forma crítica, passemos, na próxima seção, à apresentação do objeto da ideologia, pontuando os principais aspectos de sua constituição.

\section{DELIMITANDO O OBJETO DA IDEOLOGIA NA TEORIA CRÍTICA DO DISCURSO}

\subsection{DEFINIÇÃO}

$\mathrm{Na} \mathrm{TCD}$, o conceito de ideologia é fundamentalmente negativo, isto é, relaciona-se aos modos como os sentidos servem para produzir ou manter relações desiguais de poder e controle. Segundo Fairclough (1989, p. 84) 4 , a ideologia está "essencialmente vinculada a relações de poder", uma vez que se constitui como senso comum e tem como objetivo criar ou sustentar tipos de assimetrias e dominação na vida social. Dessa concepção negativa geral, Fairclough (2001, p. 121) especifica que a ideologia existe somente "nas sociedades caracterizadas por relações de dominação, com base na classe, no gênero social, no grupo cultural, e assim por diante".

Para a TCD, portanto, os processos ideológicos são concebidos enquanto representações da realidade que são edificadas em várias dimensões das "formas/sentidos das práticas discursivas e que contribuem para a produção, a reprodução ou a transformação das relações de dominação" (FAIRCLOUGH, 2001, p. 117). Esta forma crítica orienta-se, pois, por uma noção de poder em termos de hegemonia (GRAMSCI, 1971; LACLAU; MOUFFE, 1987), o que define poder como um tipo de aliança ou liderança relativamente instável entre forças diversas. Notemos que há um vínculo estreito entre hegemonia, poder e ideologia: o poder consiste na instauração de uma hegemonia, que, por sua vez, só é possível pela difusão de uma visão ou representação de mundo particular, isto é, uma ideologia, como sendo universal. Nessa direção, a TCD parte de uma concepção de ideologia que é tanto um tipo de vivência espontânea, que só pode ser rompida a partir do esforço intelectual-científico da reflexão, quanto forma discursiva e simbólica de distorção da realidade, contra a qual a crítica deve agir em um movimento de fora para dentro, revelando os processos reais de produção dos sentidos.

\subsection{LOCALIZAÇÃO}

Situando a ideologia no quadro epistemológico tridimensional do discurso da TCD (o discurso como texto, prática discursiva e prática social), formulado em 1992, Fairclough observa que as práticas discursivas, aquelas que envolvem os processos de produção, de distribuição e de consumo de textos, são formas materiais de ideologia (FAIRCLOUGH, 2001, p. 116). A ideologia é, assim, localizada tanto na macroestrutura social, sob as formas de ordens de discurso ${ }^{5}$, quanto nos eventos discursivos particulares,

\footnotetext{
${ }^{4}$ Todas as traduções de originais citados são de nossa autoria.

5 As ordens de discurso referem-se aos procedimentos, presentes em toda sociedade, de controle da produção, da seleção, da organização e da (re)distribuição do discurso, com o intuito de "conjurar seus 
sob as formas de recursos linguísticos léxico-gramaticais e fonológicos. Observemos, então, que, ao evidenciar que a ideologia é formada também em práticas discursivas, Fairclough (2001, p. 117) está chamando atenção para o fato de que é no interior dessas essas práticas onde a luta ideológica opera-se como uma de suas dimensões constitutivas.

No intervalo de mediação entre as práticas sociais, em escala macrodiscursiva, e os textos, em escala microdiscursiva, as práticas discursivas são tanto lugar de produção de ideologias, quanto espaço de desconstrução de produtos ideológicos. Com tal ênfase, Fairclough (2001) não privilegia a reprodução de ideologias, nem o movimento quase unilateral da estrutura em direção aos eventos. Em vez de focar sobre relações de estabilidade nos processos discursivos, no que diz respeito à questão ideológica, Fairclough prefere pensar esses processos em sua relação com a questão da mudança social.

Pouco tempo depois da publicação de Language and Power (originalmente publicado em 1989) e de Discourse and Social Change (originalmente publicado em 1992), Fairclough aprofunda o diálogo com a Sociologia, a Ciência Política e a Filosofia, reformulando parte de suas reflexões. Nesse novo contexto, em que o linguista aprofunda a concepção de vida social como sistema aberto, conforme disposto no Realismo Crítico de R. Bhaskar, a episteme crítica do discurso é modificada em alguns pontos. Essa mudança deve-se, especialmente, à recombinação que o autor elabora entre os conceitos de hegemonia, inspirado em A. Gramsci, de prática social e internalização de momentos, em D. Harvey, e de articulação de elementos, em E. Laclau.

A partir de Discourse in late modernity (1999) e de Analysing discourse (2003), o discurso passa a ser racionalizado como um momento no interior da prática social, não mais como ele mesmo sendo prática social. Práticas sociais são "maneiras habituais [...] pelas quais as pessoas aplicam recursos [...] para agirem sobre o mundo em conjunto" (CHOULIARAKI; FAIRCLOUGH, 1999, p. 21). No movimento de internalização e articulação entre o discurso e os demais momentos das práticas sociais, a saber, o fenômeno mental, a atividade material e as relações sociais, o discurso, enquanto semiose das práticas, é a realização simultânea de modos de agir, de representar e de identificar.

A nova localização do discurso na ontologia do social não alterou a concepção de ideologia. Em vez disso, explorou-se, mais amiúde, o princípio de que as ideologias investem discursos em todas as suas dimensões e que os processos ideológicos "são representações de aspectos do mundo que podem ser apresentados para estabelecer e manter relações de poder, de dominação e de exploração" (FAIRCLOUGH, 2003, p. 218).

\subsection{NATUREZA SEMIÓTICA}

Com base na definição e localização explicitadas acima, a constituição material da ideologia é concebida segundo algumas características que delimitam a sua natureza semiótica. A primeira característica da ideologia é a sua invisibilidade, pois ela é "mais

poderes e perigos, dominar seu acontecimento aleatório, esquivar sua pesada e temível materialidade." (FOUCAULT, 1996, p. 8).

PEIXOTO, Maria Eduarda Gonçalves; ALENCAR, Claudiana Nogueira de; FERREIRA, Ruberval. 0 objeto da ideologia na teoria crítica do discurso. Linguagem em (Dis)curso - LemD, Tubarão, SC, v. 18, n. 1, p. 215-233, jan./abr. 2018. 
efetiva quando sua ação é menos visível” (FAIRCLOUGH, 1989, p. 85). Isso significa dizer que sua eficácia consiste na naturalização de sentidos (FAIRCLOUGH, 2001, p. 117). Essa propriedade de estabilidade torna a ideologia uma dimensão imprescindível da hegemonia, à medida que "buscar ser hegemônico é tentar universalizar significados particulares, com o intuito de alcançar e de manter a dominação" (FAIRCLOUGH, 2003, p. 59). Pelo caráter estável, automático e (quase) invisível da ideologia, "não se deve pressupor que as pessoas têm consciência das dimensões ideológicas de suas práticas" (FAIRCLOUGH, 2001, p. 120). Por isso, para o autor, a consciência dos processos ideológicos na realização de determinados discursos é uma crítica (à ideologia): se alguém se torna consciente de um aspecto particular do senso comum que sustenta desigualdades de poder à própria custa, este senso "deixa de ser comum e pode perder a capacidade de manter relações de poder desiguais, isto é, sua capacidade de funcionar ideologicamente" (FAIRCLOUGH, 1989, p. 85) ${ }^{6}$.

A segunda característica da ideologia diz respeito à atuação elementar das produções ideológicas na constituição dos sujeitos, mediante processos de interpelação. Para Fairclough (2003, p. 160), os sujeitos "não são apenas preposicionados na forma como eles participam de eventos sociais e de textos, eles também são agentes sociais". Assim, o que há são sujeições contraditórias, quando "uma pessoa que opera num quadro institucional único e num único conjunto de práticas é interpelada de várias posições e puxada em direções diferentes" (FAIRCLOUGH, 2001, p. 121).

A terceira característica da ideologia é a sua eficácia, nas interações comunicativas, como efeito de textos, vinculando-se aos três significados do discurso, quais sejam, representacional, acional e identificacional. As ideologias são representações de aspectos do mundo (e, assim, têm forma em discursos) que criam ou mantêm relações de poder, podendo ser legitimadas em modos de agir (e, portanto, em gêneros que regulam práticas) e inculcadas nas identidades de agentes sociais (e, logo, em estilos). Ainda na concepção tridimensional do discurso, Fairclough (2001, p. 289) já aduzia essa percepção, quando dizia que os principais efeitos ideológicos dos discursos são "sistemas de conhecimento e crença, relações sociais e identidades sociais".

\subsection{TRATAMENTO ANALÍTICO}

Esboçadas a definição, a localização e a natureza da ideologia, passemos à discussão de como Fairclough (2003, p. 10) elabora sua proposta metodológica de análise discursiva com foco sobre os processos ideológicos da significação.

Inicialmente, de acordo com a concepção tridimensional do discurso de 1992, a ideologia é encarada como uma dimensão analítica do discurso como prática social, ao lado da hegemonia. Apesar de a ideologia constituir-se nas práticas discursivas, ela é uma categoria analítica da prática social, porque sua investigação tem o objetivo geral de

\footnotetext{
${ }^{6}$ Faz-se importante reconhecer que grupos opressores mantêm hierarquias sociais e formas de injustiça precisamente por terem consciência de aspectos do senso comum que sustentam relações desiguais de poder. Em outras palavras, "eles sabem muito bem o que estão fazendo e continuam a fazê-lo." (ŽIŽEK, 1996, p. 313).
}

PEIXOTO, Maria Eduarda Gonçalves; ALENCAR, Claudiana Nogueira de; FERREIRA, Ruberval. 0 objeto da ideologia na teoria crítica do discurso. Linguagem em (Dis)curso - LemD, Tubarão, SC, v. 18, n. 1, p. 215-233, jan./abr. 2018. 
"especificar a natureza da prática social da qual a prática discursiva é uma parte, constituindo a base para explicar por que a prática discursiva é como é, e os seus efeitos sobre a prática social" (FAIRCLOUGH, 2001, p. 289). Nesse momento inicial da TCD, a análise da ideologia, bem como da hegemonia, é realizada pelo exame i) da matriz social do discurso, que deve especificar de que modo a instância da prática social e discursiva envolve-se com estruturas e relações, ii) das ordens de discurso, com foco sobre as tendências de larga escala, como a democratização e a tecnologização, e iii) dos efeitos ideológicos e políticos do discurso.

Mais recentemente, em conformidade com a ontologia do discurso como modo de agir, de representar e de identificar, a ideologia é tratada como tema de pesquisa social, tal como questões de mudanças de espaço e tempo associadas à globalização, ao hibridismo, à cidadania e ao espaço público (FAIRCLOUGH, 2003, p. 7). No interior do enquadre metodológico-analítico da ADC (FAIRCLOUGH, 1999, p. 60), cujas diretrizes das etapas de pesquisa foram formuladas com base na Crítica Explanatória de Bhaskar (1998) e na Linguística Sistêmico-Funcional (HALLIDAY, 1970, 1994; HALLIDAY; HASAN, 1989), a categoria da ideologia ainda é tratada como instância de análise da prática social, mas considerando o novo lugar do discurso como momento da prática, conforme esclarecemos anteriormente.

$\mathrm{Na}$ atual fase de desenvolvimento, a TCD está preocupada, prioritariamente, com a dialética entre o discurso e os outros momentos das práticas sociais particulares, compreendendo o processo de internalização e de articulação, sobretudo, como estratégias de (lutas pelo) poder. Questões de poder não se ligam apenas às práticas particulares, elas estão vinculadas também às instâncias do discurso e da conjuntura social, de maneira que a análise da ideologia contempla as relações entre o momento do discurso de diferentes práticas e as distintas ordens de discurso.

Mapeada a constituição geral do objeto da ideologia na TCD, cabe trazermos à tona, adiante, alguns aspectos problemáticos em torno do conceito.

\section{ASPECTOS PROBLEMÁTICOS DA CONCEPÇÃO DE IDEOLOGIA NA TEORIA CRÍTICA DO DISCURSO}

O primeiro problema que trazemos ao debate é a fronteira que a TCD define entre processos ideológicos e produções discursivas, que arrazoa o princípio de que "nem todo discurso é irremediavelmente ideológico" (FAIRCLOUGH, 2001, p. 121). A TCD parte do princípio de que a natureza material da ideologia nas interações sociais é, parcialmente, instituída discursivamente, embora nem toda produção discursiva envolva, em algum grau, ideologia. Partindo da ideia de que há discursos que não são ideológicos, a TCD encontra um obstáculo em seu baluarte epistemológico. De um lado, tem-se a visão transformacionista da realidade social, do RC, que segue relativamente a tradição do pensamento fenomenológico da filosofia analítica, segundo o qual a realidade existe em si mesma e não pode ser revelada em sua essência e totalidade pela linguagem, pois a consciência dela é sempre um caso de percepção limitada pelos sentidos humanos e por estruturas sociais de racionalidade. De outro lado, tem-se a visão construtivista- 
interacionista, presente na teoria pós-estruturalista de E. Laclau e C. Mouffe (1987), cujo caminho de reflexão pós-marxista rompe radicalmente com o racionalismo filosófico ao compreender que a realidade em si já é construída simbolicamente, isto é, ideologicamente através de práticas discursivas articulatórias. Em outras palavras, do ponto de vista do RC, entende-se que a ideologia é uma característica que pode ser ou não investida em um discurso; já do ponto de vista de E. Laclau e C. Mouffe, não há discurso que não seja ideológico, pois a ideologia consiste na própria constituição simbólicodiscursiva da realidade.

O segundo aspecto problemático é a relação entre ideologia e formas simbólicas, no sentido de que a noção de ideologia só cabe àquelas formas simbólicas que servem para estabelecer e sustentar relações sistematicamente assimétricas de poder, conforme quer pensar a tradição marxista clássica. Ao conceber a categoria da ideologia nestes termos, a TCD nos possibilita falar de discursos que não estão engajados em lutas de poder por sua criação ou reprodução. A questão que se coloca, aqui, é, se radicalizarmos o conceito de ideologia até o limite de sua coerência, podemos notar que a noção tradicional de ideologia nos faz acreditar que há usos da linguagem imunes ao próprio contexto de tensões e conflitos sociais diversos, isto é, afirma-se que há discursos alheios aos próprios processos de luta hegemônica de instituição simbólica da realidade social, ao se constituírem à margem ou contra determinada forma de poder.

O terceiro aspecto problemático que trazemos à reflexão são as motivações ideológicas da própria prática de análise de discurso crítica, o que tornaria possível para a TCD delimitar um espaço desmistificador da crítica no interior da realidade social. A TCD está preocupada com os tipos de relações desiguais de poder que tornam as sociedades contemporâneas injustas, discriminatórias e perversas, sob distintos aspectos, e, por isso, está interessada na produção de "conhecimento que possa levar a uma mudança emancipatória" (FAIRCLOUGH, 2003, p. 210). Nessa direção, o objeto da ideologia é apropriado na TCD segundo uma leitura sintomal que o reduz a uma instância de análise que acusa as assimetrias presentes na sociedade capitalista, à maneira de um epifenômeno.

Nessa perspectiva, ideologia e crítica possuem, então, naturezas distintas, aliás, opostas. De um lado, a categoria da ideologia indica as formas simbólicas de força hegemônica, que se prestam à reprodução da ordem social e que favorecem determinados segmentos privilegiados na sociedade. De outro lado, a crítica consiste num gesto de intervenção e de contestação, movido pelo desejo de transformar, em alguma medida, o status quo de uma realidade social. É em virtude dessa forma simbólica contestatória e desafiadora, a que se refere como crítica, que a TCD projeta a sua prática de análise de discurso interpretativa. Notemos, portanto, que a crítica à ideologia, aqui, é crítica alheia à ideologia, pois a TCD não incorpora a concepção de modo mais amplo e numa situação de análise dentro da qual se poderia reconhecer a crítica mobilizada como não menos ideológica do que aquilo que ela denuncia. 
O intuito da discussão empreendida neste artigo foi descrever e discutir o enquadre conceitual de delimitação do objeto da ideologia no interior da Teoria Crítica do Discurso. De acordo com o que aduzimos ao longo deste trabalho, parece cada vez mais pertinente pensar a noção de ideologia como algo mais próximo do complexo processo de fundação simbólica e discursiva da realidade social na dimensão da práxis do que do uso de determinadas formas sígnicas para distorcer a realidade com o propósito de criar ou manter relações de poder. Nenhuma prática de intervenção e de contestação está imune ao componente ideológico, sem o qual a própria instituição simbólica da realidade social se desintegraria.

A denúncia contra o poder não é, portanto, menos ideológica do que o poder denunciado, de tal modo que a emancipação, noção motivadora de toda forma crítica, não deve apontar para a utopia da erradicação do poder, mas para a prática radicalmente crítica de jogos de poder. Disso, podemos concluir que, atualizando as palavras de Laclau (2011, p. 152), se fosse realizável uma eliminação total do poder, através da crítica da ideologia, as relações sociais seriam inteiramente transparentes, a diferença se tornaria impossível e a liberdade seria um termo redundante. Não seria esse o fim mesmo da história? O que a ampliação do conceito de ideologia, que aqui reivindicamos, faz pensar é que a emancipação não quer dizer criar estratégias de eliminação de relações de poder, mas refletir sobre de que poderes nós desejamos nos emancipar e que empoderamentos nós queremos possuir.

\section{REFERÊNCIAS}

ALTHUSSER, L. Aparelhos Ideológicos de Estado: notas sobre os aparelhos ideológicos de Estado. Rio de Janeiro: Edições Graal, 1985.

Positions. Paris: Editions Sociales, 1976.

Ideologia e Aparelhos ideológicos de Estado. Lisboa: Presença, 1970.

BHASKAR, R. General introduction. In: ARCHER, M.; BHASKAR, R.; COLLIER, A. LAWSON, T.; NORRIE. A. (Org.). Critical Realism: essencial readings. London: Routledge, 1998.

The possibility of naturalism: a philosophical critique of the contemporary human sciences.

Hemel Hempstead: Harvester Wheatsheaf, 1989.

BHASKAR, R.; CALLINICOS, A. Marxism and critical realism: a debate. Journal of Critical Realism, v. 1, n. 2, p. 89-114, 2007.

CHOULIARAKI, L.; FAIRCLOUGH, N. Discourse in late modernity: rethinking critical discourse in analysis. Edinburgh: Edinburgh University Press, 1999.

COLLIER, A. Critical Realism: an introduction to Roy Bhaskar's philosophy. London: Verson, 1994.

FAIRCLOUGH, N. Analysing Discourse: textual analysis for social research. London: Routledge, 2003.

Discurso e mudança social. Brasília: Editora UnB, 2001.

Language and power. New York: Longman, 1989.

FAIRCLOUGH, N.; JESSOP, B.; SAYER, A. Critical Realism and Semiosis. Journal of Critical

Realism, v. 5, n. 1, p. 2-10, 2002.

FOUCAULT, M. A ordem do discurso. São Paulo: Loyola, 1996.

What is Critique? In: LOTRINGER, S.; HOCHROTH, L. (Org.). The Politics of Truth. Tradução de Lysa Hochroth e Catherine Porter. Los Angeles: Semiotext(e), 1997. 
GRAMSCI, A. Selections from the Prision Notebooks. London: Lawrence \& Wishart, 1971.

HALLIDAY, M. A. K. An Introduction to Functional Grammar. 2 ed. London: Edward Arnold, 1994. Language Structure and Language Function. In: LYONS, J. (Ed.) New Horizons in Linguistics. Harmondsworth: Penguin Books, 1970.

HALLIDAY, M.; HASAN, R. Language Context and Text: aspects of language in a social-semiotic perspective. 2. ed. Oxford: Oxford University Press, 1989.

KRESS, G.; FOWLER, R. Interviews. In: FOWLER, R. et al. Language and control. London: Routledge \& Kegan Paul, 1979.

LACLAU, E. Emancipação e diferença. Rio de Janeiro: EdUERJ, 2011.

Política e ideologia na teoria marxista. Rio de Janeiro: Paz e Terra, 1979.

LACLAU, E.; MOUFFE, C. Hegemonía y Estratégia socialista: hacia una radicalización de la democracia. Madrid: Siglo XXI, 1987.

MAGALHÃES, I. Teoria crítica do discurso e texto. Linguagem em (Dis)curso, v. 4, p. 113-131, 2004.

O discurso do outro e a identidade da mulher: da colonização à década de 1990. In: BARROS, D. L. (Org.). Os discursos do descobrimento. São Paulo: Edusp, 2000.

MARX, K.; ENGELS, F. A ideologia alemã. Edição eletrônica: Ed. Ridendo Castigad Mores, 1999. PÊCHEUX, M. O mecanismo do (des)conhecimento ideológico. In: ŽIŽEK, S. (Org.) Um mapa da ideologia. Rio de Janeiro: Contraponto, 1996. 1995. Semântica e Discurso: uma crítica à afirmação do óbvio. 2. ed. Campinas: Editora da Unicamp,

PÊCHEUX, M.; FUCHS, C. A propósito da análise automática do discurso: atualização e perspectivas. In: GADET, F.; HAK, T. (Org.) Por uma análise automática do discurso: uma introdução à obra de Michel Pêcheux. Campinas: Editora da Unicamp, 1997.

SAYER, A. Realism and Social Science. London: Sage, 2000.

THOMPSON, J. B. Ideologia e cultura moderna: teoria social crítica na era dos meios de comunicação de massa. 2 ed. Rio de Janeiro: Vozes, 1995.

RAMALHO, V. Discurso e ideologia na propaganda de medicamentos: um estudo crítico sobre mudanças sociais e discursivas. 2008. 193f. Tese (Doutorado em Linguística). Programa de Pós-Graduação em Linguística, Universidade de Brasília, Distrito Federal, 2008.

ŽIŽEK, S. Um mapa da ideologia. Rio de Janeiro: Contraponto, 1996.

Recebido em: 02/05/17. Aprovado em: 07/12/17.

Title: The object of ideology in the Critical Theory of Discourse

Authors: Maria Eduarda Gonçalves Peixoto; Claudiana Nogueira de Alencar; Ruberval Ferreira

Abstract: In the second half of the twentieth century, the concept of ideology gained prominence in critical studies of language. Among the research traditions in the area, Critical Discourse Analysis differs by situating the notion of ideology at the center of its theoretical-analytical approach, especially in the area of Critical Discourse Theory (FAIRCLOUGH, 1989, 2001, 2003; CHOULIARAKI, FAIRCLOUGH, 1999). Thereunto, this paper aims to describe and discuss the conceptual constitution of the object of ideology for theory. The text presents the chronological-narrative course of the critical approach to ideology, the assumptions of the theory, the conception of ideology articulated in the theory and its problematic aspects, revealing some of the challenges that the concept implies in relation to discourse and power.

Keywords: Critique. Ideology. Discourse. Challenges. 
Título: El objeto de la ideología en la Teoría Crítica del Discurso

Autores: Maria Eduarda Gonçalves Peixoto; Claudiana Nogueira de Alencar; Ruberval Ferreira

Resumen: El concepto de ideología, en la segunda mitad del siglo XX, ha conquistado lugar de despegue en los estudios críticos del lenguaje. Entre las principales tradiciones de investigación en el área, el Análisis del Discurso Crítico, na vertiente de la Teoría Crítica del Discurso (FAIRCLOUGH, 1989, 2001, 2003; CHOULIARAKI; FAIRCLOUGH, 1999), se particulariza al situar la noción de ideología en el centro de su emprendimiento teóricoanalítico. Basado en ello, este trabajo tiene el objetivo de describir y discutir la constitución conceptual del objeto de la ideología en el interior de la teoría. Así se presentan el recorrido cronológico y narrativo del abordaje crítico de ideología, los supuestos de la teoría en foco, la concepción de ideología articulada y sus aspectos problemáticos, trayendo para la discusión algunos desafíos que el concepto implica cuánto la relación entre discurso y poder.

Palabras clave: Crítica. Ideología. Discurso. Desafíos.

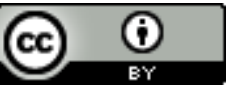

Este texto está licenciado com uma Licença Creative Commons Atribuição 4.0 Internacional

PEIXOTO, Maria Eduarda Gonçalves; ALENCAR, Claudiana Nogueira de; FERREIRA, Ruberval. 0 objeto da ideologia na teoria crítica do discurso. Linguagem em (Dis)curso - LemD, Tubarão, SC, v. 18, n. 1, p. 215-233, jan./abr. 2018. 